\title{
Combined effects of physical illness and comorbid psychiatric disorder on risk of suicide in a national population study
}

\author{
Ping Qin, Keith Hawton, Preben Bo Mortensen and Roger Webb
}

\section{Background}

People with physical illness often have psychiatric disorder and this comorbidity may have a specific influence on their risk of suicide.

\section{Aims \\ To examine how physical illness and psychiatric comorbidity interact to influence risk of suicide, with particular focus on relative timing of onset of the two types of illness.}

\section{Method}

Based on the national population of Denmark, individual-leve data were retrieved from five national registers on 27262 suicide cases and 468007 gender- and birth-date matched living controls. Data were analysed using conditional logistic regression

\section{Results}

Both suicides and controls with physical illness more often had comorbid psychiatric disorder than their physically

healthy counterparts. Although both physical and psychiatric illnesses constituted significant risk factors for suicide, their relative timing of onset in individuals with comorbidity significantly differentiated the associated risk of suicide. While suicide risk was highly elevated when onsets of both physical and psychiatric illness occurred close in time to each other, regardless which came first, psychiatric comorbidity developed some time after onset of physical illness exacerbated the risk of suicide substantially.

\section{Conclusions}

Suicide risk in physically ill people varies substantially by presence of psychiatric comorbidity, particularly the relative timing of onset of the two types of illness. Closer collaboration between general and mental health services should be an essential component of suicide prevention strategies.

\section{Declaration of interest}

None.
People who are physically ill often have psychiatric problems. The reported prevalence of depression ranges from 10 to $25 \%$ of patients with chronic physical disease $\mathrm{s}^{1-3}$ and above $30 \%$ in patients admitted to hospital with physical illness ${ }^{4}$ or severe illnesses resulting in impaired physical function. ${ }^{5,6}$ At the same time, a number of population studies have shown an increased risk of suicide associated with a range of specific physical illnesses $^{7-13}$ and with general physical ill health. ${ }^{14-16}$ A recent Danish study has further demonstrated that the elevated suicide risk associated with physical illness increased progressively with frequency and recency of admission to hospital as well as with comorbidity involving several organs or systems of the body. ${ }^{17}$

It is known that psychiatric disorder is strongly associated with risk of suicide, ${ }^{18}$ and the effect of physical illness on the risk is also important although generally less strong. ${ }^{13,15,17,19}$ The two types of illness often co-occur, ${ }^{20,21}$ but the order of development of comorbidity may vary. Little research has examined the combined effect of comorbid physical and psychiatric illnesses on risk of suicide with a large sample of the general population, ${ }^{22}$ and especially the extent to which risk varies according to whether physical illness precedes the development of psychiatric disorder or vice versa. Large-scale investigations are required for such studies to provide definitive findings.

We therefore conducted the present study utilising data from Danish population registers. Our aims were: first, to examine the nature of the comorbidity of physical and psychiatric illnesses in people dying by suicide compared with living controls; and second, to study the temporal interaction between onsets of physical illness and psychiatric disorder as well as its effect on risk of subsequent suicide.

\section{Method}

\section{Study design and participants}

This study was based on the entire population of Denmark (5.5 million), a country where hospital treatment is provided free of charge to all residents. We applied a nested case-control design to select participants, and retrieved individual-level data from five national longitudinal registers through the unique personal identifier assigned to all Danes at birth and to new immigrants in the Danish Civil Registration System. ${ }^{23}$

The Cause of Death Register ${ }^{24}$ records the cause and date of all deaths that have occurred in Denmark since 1969. It enabled us to identify all suicides $\left(n=27380\right.$, codes E950-959 in ICD- $8^{25}$ and $\mathrm{X} 60-84$ in $\mathrm{ICD}-10^{26}$ ) that occurred during the 26-year period 1981-2006. In line with previous Danish suicide studies, ${ }^{10,17,18}$ we included as study cases only deaths for which the cause of death was a definite suicide. We excluded individuals $(n=118)$ who were not residing in Denmark on 31 December of the preceding year because their socioeconomic information was incompletely recorded in the IDA database ${ }^{27}$ - a Danish acronym for the Integrated Database for Labour Market Research that contains yearly information on sociodemographic status for all residents.

Using a nested case-control design we randomly selected comparison controls through incidence density sampling, ${ }^{28}$ i.e. sampling controls from individuals who were alive and therefore at risk of suicide when their matched case died. Up to 20 controls per case, matched by gender and date of birth, were drawn from a $25 \%$ representative sample of the national population in the Civil Registration System. ${ }^{23}$ A total of 27262 suicide cases, representing 
99.6\% of all national suicides during the study period, and 468007 live controls, were included in the study.

\section{Explanatory variables and covariates}

We assessed history of physical illness through patient records in the Danish National Hospital Register. ${ }^{29}$ This register contains individual-level data on diagnosis and date of contacts with all general hospitals in Denmark from 1978 for in-patient contacts and from 1995 for out-patient contacts (visits to emergency rooms, hospital out-patient clinics and ambulance calls). Diagnoses of illness, as well as causes of death, were coded according to ICD-8 until the end of 1993 and ICD-10 thereafter (ICD-9 was not used in Denmark). For each case and control, we retrieved records of in-patient treatment for physical illness prior to the date of suicide or the matching date for controls. We excluded the following conditions from our definition of physical illness: mental and behavioural disorders (ICD-8: 290-315; ICD-10: F00-F99), pregnancy, childbirth and certain conditions of the prenatal period (ICD-8: 630-678, 760-779; ICD-10; P00-P99) and external causes (ICD-8: 800-999; ICD-10: S00-Y98, including all accidental or intentional poisonings and injuries).

To assess comorbid psychiatric disorder, we obtained personal data on contacts with psychiatric hospitals or wards, either as an in-patient or an out-patient (i.e. being treated at psychiatric emergency rooms, ambulance calls, and hospital out-patient clinics) from the Danish Psychiatric Central Register. ${ }^{30}$ This register covers all psychiatric hospitals or wards in Denmark and maintains cumulative records of in-patient contacts since 1969 and out-patient contacts since 1995 . We retrieved date of the first contact with a diagnosis of schizophrenia spectrum disorder (ICD-8: 295, 297, 298.2-298.9, 299, 301.0, 301.2, 301.83; ICD-10: F20-F29, F60.0, F60.1), affective disorder (ICD-8: 296, 298.0, 298.1, 300.4, 301.1; ICD-10: F30-F39), personality disorder (ICD-8: F60.2-F60.9; ICD-10: 301.3-301.9), substance use disorder (ICD-8: 291.9, 294.3, 303, 304; ICD-10: F10-F19) or psychiatric disorder as a broad diagnosis (ICD-8: 290-319; ICD-10: F00-F99). We considered these disorders independently and only when they were the primary diagnosis that led to hospital contact.

We also extracted personal data on sociodemographic factors (i.e. marital status, annual gross income, place of residence, citizenship) from the IDA database ${ }^{27}$ based on records for the year preceding suicide. These factors are known risk factors for suicide and psychiatric illness ${ }^{18,31}$ and were therefore included in the analyses for data adjustment.

\section{Statistical analysis}

We constructed contingency tables for variables of interest and computed the associated risk of suicide using conditional logistic regression with the PHREG procedure available in SAS version 9 for Unix, ${ }^{32}$ with each case forming a separate stratum. Conditional odds ratios and their 95\% confidence intervals (CIs) were estimated. Because we sampled controls from individuals who were alive at the point of matching and thus at risk of suicide (i.e. incidence density sampling), the estimated odds ratios from the analyses were virtually equivalent to incidence rate ratios (IRRs) generated by survival analyses of the whole cohort. ${ }^{28,33}$ The crude IRRs were adjusted only for age and gender through matching. The adjusted IRRs were further adjusted for effects of sociodemographic factors and the main effect of psychiatric history where applicable. The Wald test was used to determine the significance of relative risk against the reference group. Interaction between physical illness and psychiatric disorder was additionally examined through the likelihood ratio test. All $P$-values were two-sided and 95\% CIs were reported.

\section{Role of the funding source}

The study sponsor had no role in study design, in the collection, analysis, and interpretation of data, in the writing of the report, and in the decision to submit the paper for publication

\section{Ethical approval}

We obtained approval from the Danish Data Protection Agency to conduct the study.

\section{Results}

\section{Description of study population}

Of the 27262 people who died by suicide in Denmark during 1981-2006, 63.5\% had a recorded admission to hospital for physical illness compared with $44.5 \%$ of comparison controls $\left(\chi^{2}=3738.51, P<0.0001\right)$. Among suicide cases, those with physical illness significantly more often died from poisoning (38.1\%) compared with counterparts who did not have a recorded physical illness (31.9\%; test of differences: $\chi^{2}=107.44, P<0.0001$ ).

For both suicide cases and comparison controls, psychiatric illness (in almost all specific diagnostic groups) was significantly more common in individuals with physical illness compared with counterparts without physical illness (Table 1). Among the suicide cases, $40.8 \%$ of physically healthy and $47.2 \%$ of physically ill cases had a hospital-treated psychiatric disorder prior to suicide. The presence of psychiatric history was substantially more common in female than male cases $(P<0.0001)$.

Moreover, a substantial proportion of patients with physical illness, especially those dying by suicide, developed psychiatric disorder and had their first contact with psychiatric hospitals after being admitted to hospital for physical illness (Table 1). In both suicide cases and controls, affective disorder and substance use disorder were the most common psychiatric disorders that physically ill patients were likely to develop, whereas affective disorder and schizophrenia spectrum disorder were the two most common disorders in those without physical illness. Of patients who died from suicide, $14.0 \%$ had their first hospital contact for affective disorder and $10.0 \%$ for substance use disorder after being admitted to hospital for physical illness. Overall, $28.4 \%$ of cases had their first psychiatric hospital contact subsequent to being admitted to hospital with physical illness.

\section{Independent effects of physical illness and comorbid psychiatric illness on suicide risk}

As expected, both physical illness and psychiatric disorder constituted significant risk factors for suicide, with a crude IRR of 2.13 (95\% CI 2.07-2.18) associated with the presence of physical illness and 15.92 (95\% CI 15.47-16.39) associated with a psychiatric history. At the same time, the two types of illness interacted significantly with each other to increase suicide risk in all persons (test of interaction: $\chi^{2}=265.96, P<0.0001$ ), and in men and women separately $\left(\chi^{2}=178.00, P<0.0001\right.$ for men; $\chi^{2}=169.51, P<0.0001$ for women).

Table 2 shows the independent IRRs for suicide associated with physical illness alone, psychiatric disorder alone and comorbidity of both types of illness. Although suicide risk was highly elevated in people with psychiatric disorder, the risk was also significantly increased in those with only physical illness. More interestingly, compared with the effect of psychiatric disorder alone, comorbidity of physical illness and a pre-existing psychiatric disorder was associated with a significantly lower suicide risk (Table 3) (crude $\mathrm{IRR}=0.92$, 95\% CI 0.87-0.98, $P=0.0054)$. However, development of psychiatric disorder 


\begin{tabular}{|c|c|c|c|c|}
\hline \multirow[b]{2}{*}{ Psychiatric comorbidity } & \multicolumn{2}{|c|}{ Suicide cases } & \multicolumn{2}{|c|}{ Controls } \\
\hline & $\begin{array}{l}\text { Without physical illness } \\
\qquad \begin{array}{c}(n=9962) \\
n(\%)\end{array}\end{array}$ & $\begin{array}{l}\text { With physical illness } \\
\qquad \begin{array}{c}(n=17300) \\
n(\%)\end{array}\end{array}$ & $\begin{array}{l}\text { Without physical illness } \\
\qquad \begin{array}{c}(n=259804) \\
n(\%)\end{array}\end{array}$ & $\begin{array}{l}\text { With physical illness } \\
\qquad \begin{array}{c}(n=208203) \\
n(\%)\end{array}\end{array}$ \\
\hline $\begin{array}{l}\text { Any psychiatric illness }{ }^{a} \\
\text { Before physical illness } \\
\text { After physical illness }\end{array}$ & 4060 (40.8) & $\begin{array}{l}8164(47.2) \\
3258(18.8) \\
4906(28.4)\end{array}$ & 9273 (3.6) & $\begin{array}{r}15998(7.7) \\
8164(3.9) \\
7834(3.8)\end{array}$ \\
\hline $\begin{array}{l}\text { Affective disorder }^{\mathrm{a}} \\
\text { Before physical illness } \\
\text { After physical illness }\end{array}$ & 1731 (17.4) & $\begin{array}{l}3694(21.4) \\
1284(7.4) \\
2410(13.9) \\
\end{array}$ & 2523 (1.0) & $\begin{array}{l}4629(2.2) \\
2386(1.2) \\
2243(1.1)\end{array}$ \\
\hline $\begin{array}{l}\text { Schizophrenia spectrum disorder } \\
\text { Before physical illness } \\
\text { After physical illness }\end{array}$ & 1220 (12.3) & $\begin{array}{r}1592(9.2) \\
538(3.1) \\
1054(6.1)\end{array}$ & $2156(0.8)$ & $\begin{array}{l}2332(1.1) \\
1192(0.6) \\
1140(0.6)\end{array}$ \\
\hline $\begin{array}{l}\text { Personality disorder }^{a} \\
\text { Before physical illness } \\
\text { After physical illness }\end{array}$ & $1042(10.5)$ & $\begin{array}{c}2352(13.6) \\
949(5.5) \\
1403(8.1)\end{array}$ & $2050(0.8)$ & $\begin{array}{l}3859(1.9) \\
2019(1.0) \\
1840(0.9)\end{array}$ \\
\hline $\begin{array}{c}\text { Substance use disorder }^{a} \\
\text { Before physical illness } \\
\text { After physical illness }\end{array}$ & 949 (9.5) & $\begin{array}{c}2491(14.4) \\
762(4.4) \\
1729(10.0)\end{array}$ & $1978(0.8)$ & $\begin{array}{l}4150(2.0) \\
1681(0.8) \\
2469(1.2)\end{array}$ \\
\hline
\end{tabular}

following onset of physical illness increased the risk of suicide substantially (crude IRR $=1.50,95 \%$ CI $1.42-1.59, P<0.0001$ ). It is obvious that a subsequent psychiatric disorder, compared with a pre-existing psychiatric disorder, significantly exacerbated the risk of suicide in physically ill people (crude IRR $=1.63$, 95\% CI 1.54-1.73, $P<0.0001$ ). These findings were sustained in separate analyses for both men and women and also in the analyses adjusted for the effects of sociodemographic factors, albeit with some attenuation (Table 2 and Table 3).

\section{Influence of physical illness on risk of suicide, stratified by psychiatric status}

The overall effect of physical illness on suicide risk differed significantly according to psychiatric status, with a relatively stronger effect seen in people without than with psychiatric history $\left(\chi^{2}=541.39, P<0.0001\right)$. The IRR, after adjustment for sociodemographic factors and the main effect of psychiatric history, was 1.90 (95\% CI 1.84-1.97) for individuals without a recorded psychiatric history, 0.90 (95\% CI 0.85-0.95) for persons with a pre-existing psychiatric history, and 1.54 (95\% CI 1.461.63) for those who developed psychiatric illness after being admitted to hospital for physical illness.

More detailed assessment of the time intervals demonstrated significant variations in suicide risk depending on the precise timing and sequence of onsets for physical illness $v$. psychiatric comorbidity (Fig. 1). Suicide risk was particularly elevated when the two types of illness were first diagnosed close in time to each other, regardless which came first. For patients with physical illness and a pre-existing psychiatric disorder, the risk of suicide increased with shortening intervals between onsets of the two types of illness, and the significantly reduced risk was confined only to those with a distant psychiatric history. However, for individuals with physical illness and a subsequent psychiatric disorder, there was an attenuation of suicide risk when psychiatric treatment followed shortly after physical illness, and then the risk turned

\begin{tabular}{|c|c|c|c|c|}
\hline \multirow{2}{*}{$\begin{array}{l}\text { Physical illness } \\
\text { and comorbid psychiatric disorder }\end{array}$} & \multicolumn{2}{|c|}{ Number (\%) } & \multicolumn{2}{|c|}{ Risk for suicide $(95 \% \mathrm{Cl})$} \\
\hline & Suicide cases & Controls & Crude IRR ${ }^{\mathrm{a}}$ & Adjusted IRR ${ }^{a}$ \\
\hline \multicolumn{5}{|l|}{ Total ( $n=27262$ cases, 468007 controls) } \\
\hline Neither physical nor psychiatric illness & $5902(21.7)$ & $250531(53.5)$ & 1 (reference) & 1 (reference) \\
\hline Physical illness only & $9136(33.5)$ & 192205 (41.1) & $1.94(1.88-2.01)$ & $1.90(1.84-1.97)$ \\
\hline Psychiatric disorder only & $4060(14.9)$ & $9273(2.0)$ & $20.02(19.11-20.99)$ & $15.66(14.92-16.43)$ \\
\hline Psychiatric disorder before physical illness & $3258(11.9)$ & $8164(1.7)$ & $18.47(17.56-19.43)$ & 14.05 (13.33-14.80) \\
\hline Psychiatric disorder after physical illness & $4906(18.0)$ & $7834(1.7)$ & $30.10(28.70-31.56)$ & $24.16(23.00-25.36)$ \\
\hline \multicolumn{5}{|l|}{ Men ( $n=18099$ cases, 307729 controls) } \\
\hline Neither physical nor psychiatric illness & $4726(26.1)$ & $173475(56.4)$ & 1 (reference) & 1 (reference) \\
\hline Physical illness only & $6459(35.7)$ & $118996(38.7)$ & $1.82(1.75-1.90)$ & $1.78(1.71-1.85)$ \\
\hline Psychiatric disorder only & $2564(14.2)$ & $6109(2.0)$ & $16.45(15.55-17.40)$ & $12.22(11.52-12.95)$ \\
\hline Psychiatric disorder before physical illness & $1680(9.3)$ & 4548 (1.5) & $14.05(13.16-15.00)$ & $9.94(9.29-10.65)$ \\
\hline Psychiatric disorder after physical illness & $2670(14.7)$ & $4601(1.5)$ & $22.84(21.52-24.24)$ & $17.34(16.30-18.43)$ \\
\hline \multicolumn{5}{|l|}{ Women ( $n=9163$ cases, 160278 controls) } \\
\hline Neither physical nor psychiatric illness & $1176(12.8)$ & $77056(48.0)$ & 1 (reference) & 1 (reference) \\
\hline Physical illness only & $2677(29.2)$ & 73209 (45.7) & $2.49(2.32-2.68)$ & $2.48(2.31-2.66)$ \\
\hline Psychiatric disorder only & $1496(16.4)$ & $3164(2.0)$ & $33.03(30.25-36.06)$ & $28.24(25.82-30.89)$ \\
\hline Psychiatric disorder before physical illness & $1578(17.2)$ & $3616(2.3)$ & $31.69(29.05-34.57)$ & $26.77(24.49-29.27)$ \\
\hline Psychiatric disorder after physical illness & $2236(24.4)$ & $3233(2.0)$ & $53.26(48.89-58.01)$ & $46.74(42.85-50.99)$ \\
\hline
\end{tabular}




\begin{tabular}{|c|c|c|}
\hline Timing of physical illness $v$. psychiatric disorder & Crude IRR $^{\mathrm{a}}(95 \% \mathrm{Cl})$ & Adjusted IRR ${ }^{\mathrm{a}}(95 \% \mathrm{Cl})$ \\
\hline \multicolumn{3}{|l|}{ Total } \\
\hline Psychiatric before physical $v$. psychiatric only & $0.92(0.87-0.98)^{*}$ & $0.90(0.85-0.95)^{*}$ \\
\hline Psychiatric after physical $v$. psychiatric only & $1.50(1.42-1.59)^{*}$ & $1.54(1.46-1.63)^{*}$ \\
\hline Psychiatric after physical $v$. psychiatric before physical & $1.63(1.54-1.73)^{*}$ & $1.72(1.62-1.82)^{*}$ \\
\hline \multicolumn{3}{|l|}{ Men } \\
\hline Psychiatric before physical $v$. psychiatric only & $0.85(0.79-0.92)^{*}$ & $0.81(0.76-0.88)^{*}$ \\
\hline Psychiatric after physical v. psychiatric only & $1.39(1.30-1.49)^{*}$ & $1.42(1.32-1.52)^{*}$ \\
\hline Psychiatric after physical $v$. psychiatric before physical & $1.63(1.51-1.76)^{*}$ & $1.74(1.61-1.89)^{*}$ \\
\hline \multicolumn{3}{|l|}{ Women } \\
\hline Psychiatric before physical v. psychiatric only & $0.96(0.88-1.05)$ & $0.95(0.87-1.04)$ \\
\hline Psychiatric after physical v. psychiatric only & $1.61(1.48-1.76)^{*}$ & $1.66(1.52-1.81)^{\star}$ \\
\hline Psychiatric after physical $v$. psychiatric before physical & $1.68(1.54-1.83)^{\star}$ & $1.75(1.60-1.90)^{*}$ \\
\hline
\end{tabular}

to increase steadily when psychiatric illness developed some years after physical illness. These patterns were replicated in analyses stratified by gender.

\section{Discussion}

\section{Key findings and interpretations}

To our knowledge, this is the first study to document the extent to which psychiatric comorbidity in physically ill individuals contributes to risk of suicide, and to assess the temporal nature of this comorbidity effect. It shows that people dying by suicide (and also living controls) with physical illness had a higher prevalence of comorbid psychiatric illness than their physically healthy counterparts. A substantial proportion of physically ill people, especially those who died by suicide, had their first contact with psychiatric services after being treated in hospital for physical illness. Although physical and psychiatric illnesses both constituted significant risk factors for suicide, the two types of illness significantly interacted with each other and the temporal relationship between them differentially influences the risk of suicide. People with both types of illness were especially prone to dying by suicide if the two types of illness were first diagnosed close in time to each other, regardless which came first, and if onset of psychiatric disorder developed some years after the diagnosis of physical illness. These results held for both men and women.

Our findings support previous evidence of high comorbidity of mental and physical health problems ${ }^{1-3,21}$ and a strong correlation between physical symptoms and psychological distress. ${ }^{34}$ In the complexity of physical and psychiatric comorbidity, growing evidence suggests that biological mechanisms underlie a bi-directional link between many medical illnesses and psychiatric disorders such as depression. ${ }^{20,35}$ Co-occurring psychiatric illness may be symptomatic of an underlying medical condition, and could also

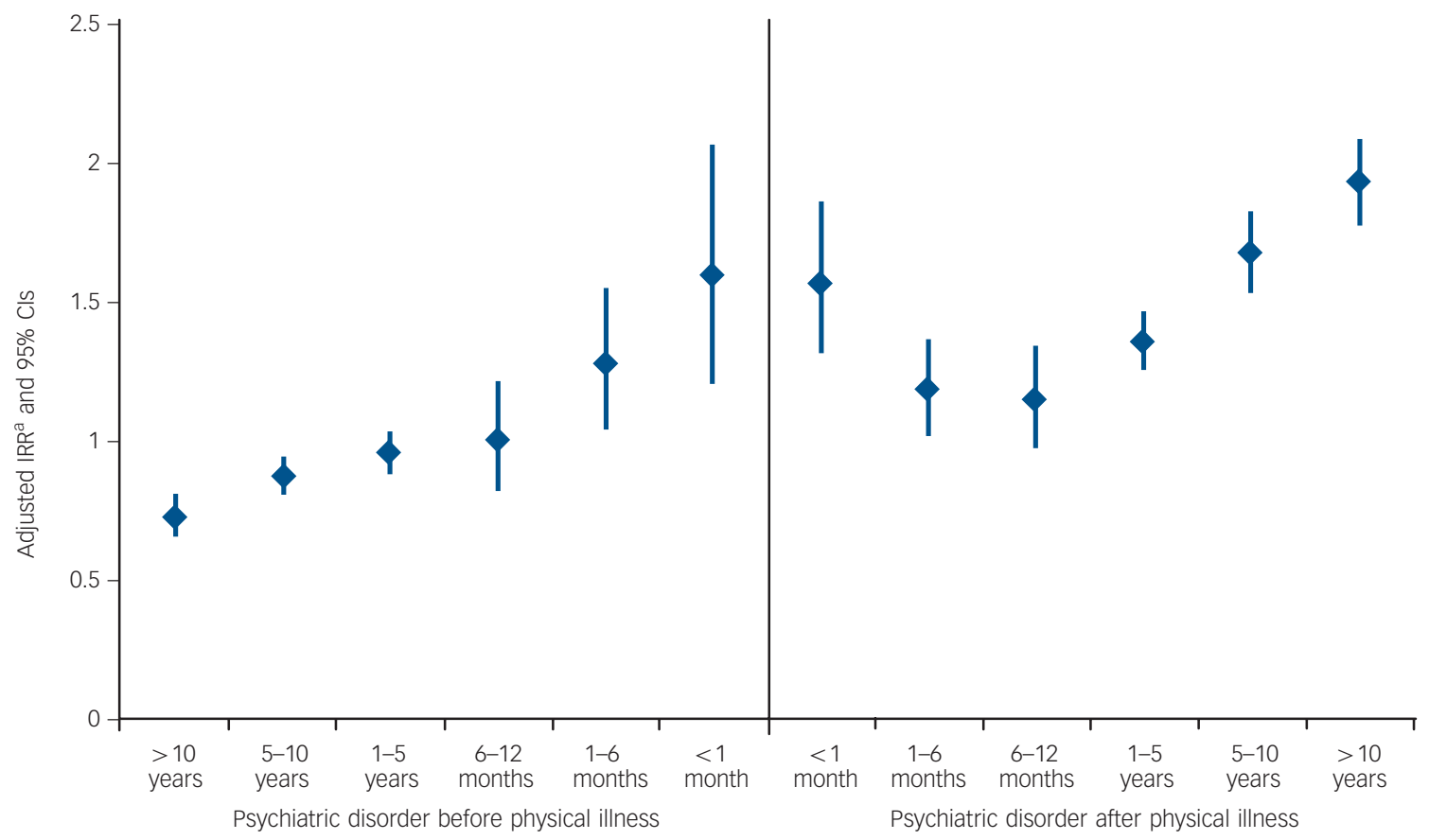

Fig. 1 Temporal variation in relative risk of suicide according to time interval and sequence of physical illness and psychiatric comorbidity.

a. Incident rate ratios (IRRs) were estimated using people with only psychiatric disorder as the reference group and adjusted for the effects of sociodemographic factors. 
be induced by substance use or medication. ${ }^{5,6}$ However, our study also indicates that a large proportion of physically ill patients developed a psychiatric disorder necessitating presentation to a psychiatric hospital after being treated for physical illness, and this was particularly so in suicide cases. These findings suggest an important mediating role of comorbid psychiatric illness as the link between physical illness and risk of suicide.

Previous studies of psychiatric comorbidity in people with physical illnesses have mostly focused on depression, ${ }^{1-3,13}$ with little attention being paid to other diagnostic groups. In this study, comorbid psychiatric disorder involved not only affective disorder (mainly depression), but also conditions such as personality disorder and schizophrenia spectrum disorder. Substance use disorder, mostly diagnosed following onset of physical illness, was the second most prevalent psychiatric condition in patients with physical illness, particularly in those who died by suicide. Although the misuse of substances might be present previously, one possible explanation of the high prevalence could be that alcohol and drugs are often used to help ease painful symptoms or distressed mood induced by physical illness, resulting in addictions requiring hospital treatment. In line with this notion, we found that physically ill people more often used poisoning as the method for suicide compared with those without a recorded physical illness. Such a finding is interesting, although not unexpected, because people with physical illness have easier accesses to medication used for treating the illness and for controlling associated symptoms such as pain and insomnia, as well as for treatment of comorbid psychiatric disorders when present. It is also suggestive of an increase in acquired capacity for suicide as a result of greater habituation to pain or medical procedures. ${ }^{36,37}$ Although we could not ascertain whether the substances used for poisoning were the medications used to treat the relevant physical illnesses, this finding highlights the need for careful management and control over medication used to treat physical illness, especially when comorbid psychiatric disorder is present.

The strong interactive influence we found between comorbid physical and psychiatric illness on suicide risk concurs with evidence that physical and psychiatric comorbidity is strongly associated with high levels of distress, worsening of quality of life and prognosis of physical illness. ${ }^{38-40}$ Our results are, however, the first we are aware of to demonstrate significant temporal variations of suicide risk according to the time interval and the sequence of physical illness and psychiatric comorbidity. A combination of physical illness and long-standing pre-existing psychiatric history is linked with a lower suicide risk compared with having a psychiatric history alone; however, the risk increases with shortening intervals between having both types of illness. At the same time, being treated for psychiatric disorder shortly after physical illness attenuates the elevated risk for suicide, but development of psychiatric disorder some years after physical illness increases suicide risk substantially. These findings are interesting and clinically meaningful. It is usually anticipated that presence of comorbid psychiatric illness is predictive of worse outcomes of physical illness and increased mortality, ${ }^{38-40}$ and that patients with severe mental illness have worse physical health and shorter life expectancy in comparison with the general population. ${ }^{20,41}$ Our findings further indicate that the influence of physical and psychiatric comorbidity on suicide risk differs according to whether psychiatric illness was already present before physical illness or developed after the diagnosis of physical illness, suggesting a differential effect of the temporal relation of the two types of illness on patients' risk of suicide. It seems likely that treatment of physical illness may have a beneficial effect on pre-existing psychiatric illnesses or onsets, thus weakening the highly elevated risk of suicide associated with existing psychiatric illness. In contrast, development of a psychiatric illness in someone who has been physically ill for a long period may reflect a worsening physical condition and thus have an effect on exacerbating the patient's wish to die. These results emphasise the need for active screening and treatment of psychiatric disorder in people with physical illness, plus vigilance of the development of hopelessness and possible suicidal ideation. Not only may this improve a patient's welfare, it may also contribute to suicide prevention.

\section{Strengths and limitations}

Major strengths of this study include its coverage of the entire national population of Denmark and the utility of data collected systematically without a specific research purpose. This ensures the full representation of a national population and minimises possible biases often induced by recall of information and selected access to healthcare, thus making the results highly generalisable, especially to countries or regions with comparable social settings. Also, the collection of data on psychiatric history began in $1969^{30}$ - almost 10 years earlier than the beginning of data collection for physical illness in 1978. ${ }^{29}$ This makes the identified first contact for psychiatric disorder after the diagnosis of physical illness more likely to be a new case with psychiatric disorder that required presentation to a psychiatric hospital.

This study has also limitations. First, we considered only serious physical illnesses that resulted in admission to hospital for treatment, which may act as a useful proxy of serious physical illness on one hand, but also leave the influence of mild physical illnesses unascertained. Similarly, we used psychiatric hospital contact as a proxy for psychiatric status, which underestimates the full extent of psychiatric disorders and only reflects more serious disorders. Additionally, we were able to obtain individual data on physical illness only starting in 1978 when the Danish National Hospital Registry was established. Thus, our data cover a relatively long period, but do not enable measurement of cumulative lifetime prevalence for older persons. We should also note that the shorter coverage period of data on physical illness than that for psychiatric contact may have some influence on the results. It could be that an individual could have had physical illness during that period (1969-1978) that was comorbid with mental illness but the issue of comorbidity and sequencing during that period remains unaccounted for in the analyses.

Although there are many robust findings in this study, we have primarily examined all illnesses together and therefore obtained the estimates of the average of illnesses in the current study. Given the large sample size, some of the significant findings may not have strong clinical significance. Further analyses looking into whether the interval between physical and mental illnesses predicts the time to suicide from the onset of comorbidity, and the joint effect of specific physical diseases and psychiatric disorders may provide more insights. Also, it may be worthwhile and clinically informative to profile in detail methods used for suicide by physically ill people and to test potential psychological and/or biological theories underlining the relationship between physical illness and suicidal behaviour.

\section{Clinical implications}

The role of physical illness as a risk factor for suicide has received relatively little consideration in suicide prevention strategies. ${ }^{42}$ Our findings clearly indicate that people with physical illnesses should receive greater attention in this respect, especially those who subsequently become mentally ill. The findings also highlight 
the need for closer integration of clinical services for somatic and mental health. Clinicians treating people with physical illness should ensure that appropriate local services are available to respond to the medical, emotional and practical needs of people with physical illness. They should also receive training in detection of people at risk of suicide to facilitate early referral where necessary to mental health services. High-quality liaison psychiatric services at both hospital and community care levels ${ }^{42}$ should be a component of suicide prevention strategies.

Ping Qin, MD, PhD, National Centre for Register-based Research, Aarhus University, Denmark, and National Centre for Suicide Research and Prevention, Institute of Clinical Medicine, University of Oslo, Norway: Keith Hawton, DSC, DM, Centre for Sucict St, Mortensen, $M D$, Din University, Denmark; Roger Webb, MSc, PhD, Centre for Mental Health and Risk University of Manchester, UK

Correspondence: Professor Ping Qin, National Centre for Suicide Research and Prevention, Institute of Clinical Medicine, University of Oslo, Sognsvannsveien 21, N-0372 Oslo, Norway. Email: ping.qin@medisin.uio.no

First received 6 Mar 2013, final revision 17 Oct 2013, accepted 6 Nov 2013

\section{Funding}

The study was funded by the Sygekassernes Helsefonden (National Health Insurance Foundation) in Denmark (2009B063). K.H. is a National (England) Institute of Research Senio Investigator.

\section{References}

1 Dersh J, Polatin PB, Gatchel RJ. Chronic pain and psychopathology: research findings and theoretical considerations. Psychosom Med 2002; 64: 773-86.

2 Koenig HG, George LK, Peterson BL, Pieper CF. Depression in medically ill hospitalized older adults: prevalence, characteristics, and course of symptoms according to six diagnostic schemes. Am J Psychiatry 1997; 154 1376-83.

3 Moussavi S, Chatterji S, Verdes E, Tandon A, Patel V, Ustun B. Depression, chronic diseases, and decrements in health: results from the World Health Surveys. Lancet 2007; 370: 851-8.

4 Peveler R, Carson A, Rodin G. Depression in medical patients. BMJ 2002; 325 149-52.

5 Irving G, Lloyd-Williams M. Depression in advanced cancer. Eur J Oncol Nurs 2010; 14: 395-9.

6 Block SD. Diagnosis and treatment of depression in patients with advanced illness. Epidemiol Psichiatr Soc 2010; 19: 103-9.

7 Allebeck $P$, Bolund $C$, Ringback $G$. Increased suicide rate in cancer patients. A cohort study based on the Swedish Cancer-Environment Register. J Clin Epidemiol 1989; 42: 611-6.

8 Bronnum-Hansen $\mathrm{H}$, Stenager E, Nylev SE, Koch-Henriksen N. Suicide among Danes with multiple sclerosis. J Neurol Neurosurg Psychiatry 2005; 76: 1457-9.

9 Larsen KK, Agerbo E, Christensen B, Sondergaard J, Vestergaard M. Myocardial infarction and risk of suicide: a population-based case-control study. Circulation 2010; 122: 2388-93.

10 Qin $\mathrm{P}$, Mortensen PB, Waltoft BL, Postolache TT. Allergy is associated with suicide completion with a possible mediating role of mood disorder a population-based study. Allergy 2011; 66: 658-64.

11 Tseng $\mathrm{CH}$. Mortality and causes of death in a national sample of diabetic patients in Taiwan. Diabetes Care 2004; 27: 1605-9.

12 Cote TR, Biggar RJ, Dannenberg AL. Risk of suicide among persons with AIDS A national assessment. JAMA 1992; 268: 2066-8.

13 Webb RT, Kontopantelis E, Doran T, Qin P, Creed F, Kapur N. Suicide risk in primary care patients with major physical diseases: a case-control study. Arch Gen Psychiatry 2012; 69: 256-64.

14 Pirkis J, Burgess $P$. Suicide and recency of health care contacts. A systematic review. Br J Psychiatry 1998; 173: 462-74.

15 Hawton K, van Heeringen K. Suicide. Lancet 2009; 373: 1372-81.

16 Kaplan MS, McFarland BH, Huguet N, Newsom JT. Physical illness, functional limitations, and suicide risk: a population-based study. Am J Orthopsychiatry 2007; 77: 56-60
17 Qin P, Webb R, Kapur N, Sorensen HT. Hospitalization for physical illness and risk of subsequent suicide: a population study. J Intern Med 2013; 273 48-58.

18 Qin P, Agerbo E, Mortensen PB. Suicide risk in relation to socioeconomic demographic, psychiatric, and familial factors: a national register-based study of all suicides in Denmark, 1981-1997. Am J Psychiatry 2003; 160: 765-72.

19 Qin P, Agerbo E, Mortensen PB. Factors contributing to suicide: the epidemiological evidence from large-scale registers. In Prevention and Treatment of Suicidal Behaviour: From Science to Practice (ed. K Hawton): 11-28. Oxford University Press, 2005

20 Laursen TM, Munk-Olsen T, Gasse C. Chronic somatic comorbidity and excess mortality due to natural causes in persons with schizophrenia or bipolar affective disorder. PLOS One 2011; 6: e24597.

21 Dixon L, Postrado L, Delahanty J, Fischer PJ, Lehman A. The association of medical comorbidity in schizophrenia with poor physical and mental health. J Nerv Ment Dis 1999; 187: 496-502.

22 Goodwin RD, Marusic A, Hoven CW. Suicide attempts in the United States: the role of physical illness. Soc Sci Med 2003; 56: 1783-8.

23 Pedersen CB, Gotzsche H, Moller JO, Mortensen PB. The Danish Civil Registration System. A cohort of eight million persons. Dan Med Bull 2006; 53: 441-9.

24 Juel K, Helweg-Larsen K. The Danish registers of causes of death. Dan Med Bull 1999; 46: 354-7

25 World Health Organization. The International Classification of Diseases, Eighth Revision (ICD-8). WHO, 1965

26 World Health Organization. The International Classification of Diseases, Tenth Revision (ICD-10). WHO, 1990.

27 Statistik D. IDA - en integreret database for arbejdsmarkedsforskning. Danmarks Statistiks trykkeri, 1991.

28 Clayton D, Hills M. Statistical Models in Epidemiology. Oxford University Press, 1993.

29 Andersen TF, Madsen M, Jorgensen J, Mellemkjoer L, Olsen JH. The Danish National Hospital Register. A valuable source of data for modern health sciences. Dan Med Bull 1999; 46: 263-8.

30 Munk-Jorgensen $\mathrm{P}$, Mortensen PB. The Danish Psychiatric Central Register Dan Med Bull 1997; 44: 82-4.

31 Agerbo E, Byrne M, Eaton WW, Mortensen PB. Marital and labor market status in the long run in schizophrenia. Arch Gen Psychiatry 2004; 61: 28-33.

32 SAS Institute. The PHREG Procedure. In SAS/STAT9(R) 9.2 User's Guide, Second Edition. SAS Institute, 2013 (http://support.sas.com/documentation/ cdl/en/statug/63033/HTML/default/viewer.htm\#statug_phreg_sect001.htm).

33 King G, Zeng L. Estimating risk and rate levels, ratios and differences in casecontrol studies. Stat Med 2002; 21: 1409-27.

34 Watson D, Pennebaker JW. Health complaints, stress, and distress: exploring the central role of negative affectivity. Psychol Rev 1989; 96: 234-54.

35 Evans DL, Charney DS, Lewis L, Golden RN, Gorman JM, Krishnan KR, et al. Mood disorders in the medically ill: scientific review and recommendations. Biol Psychiatry 2005; 58: 175-89.

36 Joiner Jr TE, Van Orden KA, Witte TK, Selby EA, Ribeiro JD, Lewis $\mathrm{R}$, et al. Main predictions of the interpersonal-psychological theory of suicidal behavior: empirical tests in two samples of young adults. $J$ Abnorm Psychol 2009; 118: 634-46.

37 Ribeiro JD, Joiner TE. The interpersonal-psychological theory of suicidal behavior: current status and future directions. J Clin Psychol 2009; 65 1291-9.

38 Pirkola S, Saarni S, Suvisaari J, Elovainio M, Partonen T, Aalto AM, et al. General health and quality-of-life measures in active, recent, and comorbid mental disorders: a population-based health 2000 study. Compr Psychiatry 2009; 50: 108-14.

39 Baumeister $\mathrm{H}$, Balke $\mathrm{K}$, Harter M. Psychiatric and somatic comorbidities are negatively associated with quality of life in physically ill patients. J Clin Epidemiol 2005; 58: 1090-100.

40 von Ammon CS, Furlanetto LM, Creech SD, Powell LH. Medical illness, past depression, and present depression: a predictive triad for in-hospital mortality. Am J Psychiatry 2001; 158: 43-8.

41 Leucht S, Burkard T, Henderson J, Maj M, Sartorius N. Physical illness and schizophrenia: a review of the literature. Acta Psychiatr Scand 2007; 116 : 317-33.

42 Bazalgette L, Bradley W, Ousbey J. The Truth About Suicide. DEMOS, 2012 